\title{
MATAURA IN SOUTHLAND, NEW ZEALAND: A SUSTAINABLE PROJECT
}

\section{Alana Fitzgerald, Ciarain Gordon, Danielle Kitto, Charlotte Ma, Aimee Mackie, Angela McKnight, Alice Restieaux, Amy Wilson and Laurie Mahoney}

\section{INTRODUCTION}

This report outlines the community assessment, health interventions and recommendations, along with an evaluation of the Mataura district, proposed by a group of Year 3 students from the School of Nursing at Otago Polytechnic over a four-week period in April 2019.

Mataura is a small settlement situated on the Mataura River on the eastern edge of the Southland Plain. According to the 2013 New Zealand census, the population of

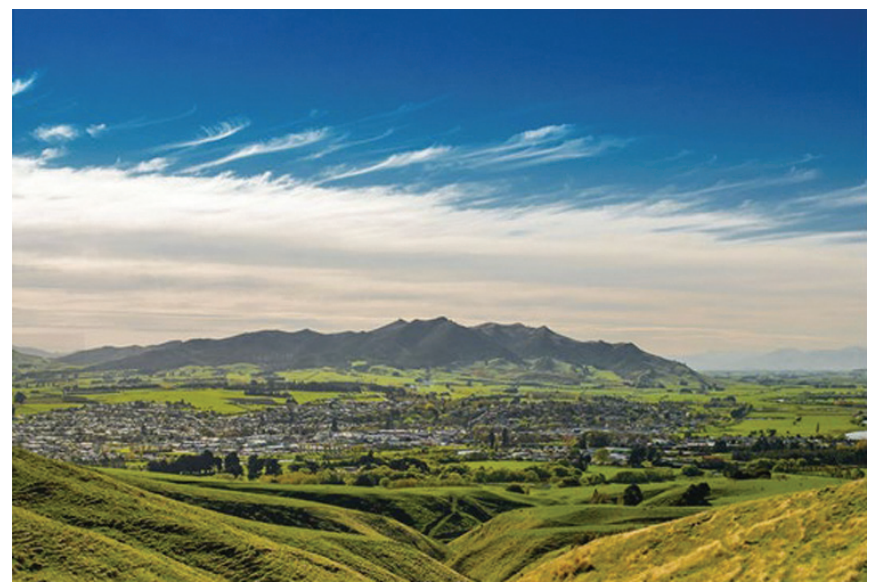

Figure I. "Our people, our community." Image retrieved from https://mataura.com. Source: Authors.

Mataura is 1509 (Statistics New

Zealand, 20I3). In Mataura, the most common ethnic group is European; the second most common group is Māori, with 29.6 percent of residents identifying as Māori (Statistics New Zealand, 20 I 3). Historically, sheep, cattle and dairy farming have been practiced on the surrounding plains. Logging and timber mills once operated in the forested hills to the east. The Mataura River is internationally renowned for brown trout fly fishing (Grant, 20I5).

Through visiting Mataura, conducting a foot survey and interviewing members of the community, some key health needs became apparent to the group. We discovered that the most at-risk population groups within the community are Māori, children and adolescents, shearers, immigrants and the elderly. The main health needs identified by community members were dental caries in children and psychosocial issues in adolescents. In order to address these issues, we developed a health promotion resource for each. To address dental caries in children, we created a health promotion poster, fridge magnets and a tooth-brushing chart. The key health message in our resource is the need to brush teeth twice a day, look after your smile and that baby teeth matter.

To address psychosocial issues in adolescents, we decided to focus on depression. We chose this issue as, in this age group, the signs and symptoms of depression are often not recognised (Thapar, Collishaw, Pine, \& Thapar, 20I2). We decided to make a health promotion poster and a bookmark that included signs, symptoms and resources 
focused on depression. The key message in this resource is the need to look after yourself; we wanted to give adolescents the information and tools to recognise if they were feeling low, what to do and where to seek help.

Category B ethical approval was granted through the Otago Polytechnic Ethics Committee, including Maori consultation with the Kaitohutohu office at Otago Polytechnic.

\section{Needs Analysis}

Through research, consultation and a community assessment, we identified six groups within the community which are vulnerable to poor health: Māori, children, adolescents, shearers, immigrants and the elderly.

- According to the 2013 census, Mãori make up 30 percent of Mataura's population. Health inequalities experienced by Mãori in New Zealand are greater than those for non- Māori. Māori have lower immunisation rates, a lower incidence of screening

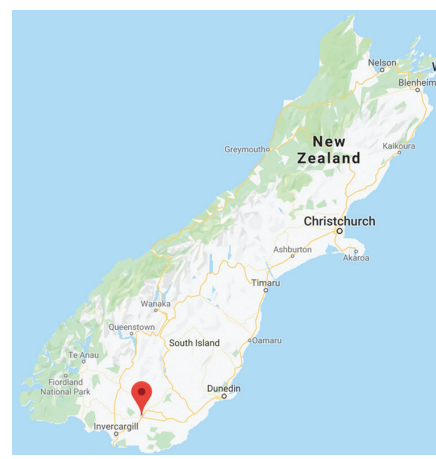

Figure 2. Mataura, Southland. Image credit for figure 2. Mataura,

Southland. Image retrieved from https://www.google.co.nz/maps/place/

Mataura/@-44.1248942,I68.45869|8,6z/ data $=! 4 \mathrm{~m} 5 ! 3 \mathrm{~m} 4$ ! I s0 $\times$ a82 cd I $5273 \mathrm{a} 3$ 6cb5:0×500ef8684798c30!8m2!3d-

46.1934288 !4d I 68.8660I 55 . for health conditions, and less engagement in health services (Personal communication, April 3, 2019).

- Children are identified as a vulnerable group due to their age and reliance on adults (WHO, 2019c).

- Adolescents are a vulnerable group within this community, with psychosocial issues the main cause for concern. Problems include anxiety, depression, truancy and gang affiliation.

The most common reasons that the vulnerable groups identified failed to access appropriate healthcare in Mataura were low socioeconomic status, mental health conditions, low health literacy, and a lack of services that are acceptable, accessible, affordable, appropriate and available.

\section{Identified health needs chosen to pursue}

We chose two health issues to investigate that we heard spoken about most frequently:

- Dental caries among children

- Psychosocial issues among children aged II-|4.

Our project was based on the Ottawa Charter, enabling us to create resources to build healthy public policy, create supportive environments, strengthen community action, develop personal skills and promote health in order to prevent illness. Our aim was to ensure that local people could have access to education and resources that would facilitate, control and improve the oral health of children and manage depression among adolescents in the community (WHO, 2019a).

\section{HEALTH NEED I - ORAL HEALTH IN NEW ZEALAND}

While on primary health placement doing a community assessment of Mataura, we established through talking with health professionals that dental health was a major concern in the area, especially in relation to children. While dental care is free to all eligible children until they reach 18 , there is still a high prevalence of poor oral health in New Zealand children (Everything New Zealand, 2019). Māori have higher rates of health inequalities in general, and oral health is no exception. In this literature review, we discuss the factors that contribute to poor oral health, 
the importance of a fluoridated drinking water supply, barriers to parents taking their children to the dentist for caries prevention and treatment, and why Māori have higher rates of poor oral health.

In 2018, there were more than 96,000 New Zealand children with overdue dental checks (New Zealand Herald, 2018). Dr Bill O'Connor, president of the New Zealand Dental Association (NZDA), spoke at the association's 2018 annual conference about the need to improve dental services in schools: "Children don't get to choose what they eat or drink, they don't choose to have rotten teeth and the pain and suffering that comes with that. "They don't choose to live in areas that are woefully unable to meet the treatment needs of their population ...." (Martin, 2018, para. 8).

Dental caries is one of the most common preventable childhood diseases and is the mjaor cause of poor oral health in children (Hunt et al., 20/8). Caries is caused when bacteria in the mouth, present for prolonged periods, begins to 'eat away' at the teeth, leading to tooth decay (Colgate, n.d.). If there is no treatment, the cavities can progress beneath the tooth enamel and into the core layers of the tooth (Martin, 2018).

Early childhood caries disrupts the day-to-day lives of children, causing chronic pain, disrupted sleep, changes in eating patterns and altered growth (Hunt et al., 2018). Insufficient oral care, including not brushing teeth twice a day, can cause them to decay. Another main contributor to tooth decay are unhealthy eating habits, especially foods, drinks and sweets that are high in sugar.This creates the ideal breeding ground for bacteria to grow (Colgate, n.d.). According to Dentist Dr Rob Beaglehole, a spokesman for the NZDA, sugar is the leading factor in the development of tooth decay (NZDA, 2017).

The Ministry of Health has provided simple guidelines to prevent dental caries in children:

I. Ensure that teeth are brushed twice a day

2. Have regular dental check-ups

3. Limit sugary drinks and promote healthy snacks

It is well documented that Māori have higher rates of poor oral health in New Zealand (Stuart, Gilmour, Broadbent, \& Robson, 20l I). Factors identified as barriers to good oral health in the Māori population are smoking, alcohol use, sugary diets and frequent snacking and poor nutrition (Harris, Nicoll, Adair, \& Pine, 2004). For this group, dental caries is a result of poor oral health habits such as not brushing teeth adequately or frequent use of a recommended fluoridated toothpaste, and failure to visit a dentist to maintain dental hygiene (Harris et al., 2004). Other social factors that influence dental health are lower socioeconomic status, lack of education and living in areas that lack a fluoridated water supply (Harris et al., 2004). Together, these factors contribute to the difficulties in developing effective preventative strategies to address inequalities in dental care.

In New Zealand, early childhood caries is the leading cause of chronic disease and hospital admissions for children (Bach \& Manton, 20l4). The consequences of chronic dental conditions in children are localised infections leading to facial cellulitis, pain leading to disrupted sleep patterns, behavioural problems and missing school (Broughton et al., 20 I3). Severe dental caries can also affect the growth and development of children under five (Bach et al., 20 I 4). One tooth with decay that effects the nerve has been shown to reduce weight by I kilogram in preschool children (Schluter et al., 2016).

\section{The importance of a fluoridated drinking water supply}

Fluoride is a mineral that occurs naturally in many places (Colgate, 2019). Fluoride is frequently added to drinking water supplies around the world to prevent tooth decay and dental caries in the local population (Colgate, 2019).

Fluoride prevents and reduces tooth decay and dental caries in a number of ways: it inhibits the demineralisation of tooth structure, promotes the remineralisation of tooth structure, inhibits bacterial plaque action and fortifies the 
enamel of developing teeth - all of which strengthens teeth, making them much more resistant to caries (Hassan, 2018; Messina, 2016). For continued protection, children and adults need both systematic and topical fluoride application (Messina, 2016). Topical fluoride refers to fluoride toothpaste, while systematic fluoride is obtained through drinking water with added fluoride (Messina, 2016).

In some places, fluoridation of drinking water supplies has reduced the incidence of dental caries in children's developing teeth by as much as 60 percent (Messina, 2016). When fluoride is ingested with water, it is absorbed and then secreted in the saliva where it inhibits enamel demineralisation and prevents dental caries and tooth decay. $\mathrm{A}$ constant low level of fluoride in the mouth has been proven to benefit oral health and prevent the effects of plaque bacteria on the teeth (Royal Society of New Zealand, 20I4).

Because New Zealand water supplies have low natural fluoride levels (Royal Society of New Zealand, 20I4), fluoride is added to the water supply for oral health reasons. These levels of added fluoride are set on the basis of research and data derived from animal and human toxicology studies; the levels of fluoride in drinking water provide maximum benefits for oral health, with no adverse effects (Royal Society of New Zealand, 20 I 4).

It appears that misinformation and fear of the effects of fluoride at high levels have made places like Southland wary of adding fluoride to the water supply. Even though the Ministry of Health has urged Southland towns to fluoridate their water, they have consistently refused to do so (McLeod, 2016). Unfortunately, this has created a health issue for preschoolers and young children in the province, whose oral health has been negatively influenced (Personal communication, April 3, 2019). Unfluoridated towns in Southland have a much greater incidence of tooth decay and dental caries than places with fluoridated water.

\section{Barriers}

Oral health remains a neglected area in Mataura. The situation is not helped by the various barriers to the delivery of oral health services to children living in rural locations (Personal communication, April 3, 2019).

\section{Accessibility}

There is a lack of available services for certain groups in this rural area (Personal communication, April 3, 2019). A mobile dental clinic visits Mataura for only six weeks each year to provide annual check-ups and dental treatment for children (Southern District Health Board, 2019). Apart from the mobile clinic, there is no dental service in Mataura; parents and their children must arrange transport to Gore for dental appointments (Personal communication, April 3, 20 19). There are geographical barriers - Gore is $12.3 \mathrm{~km}$ from Mataura (Google, n.d.). Transport and time factors were reported as barriers for some whānau; they had difficulties in making appointments for their children, as the dental clinic was closed at weekends, which are usually their 'free' days to take their children to the clinic (Personal communication, April 3, 2019).

\section{Acceptability}

Lack of culturally competent care and culturally safe service are likely to delay or prevent whānau seeking healthcare (Personal communication, April 3, 2019). Late diagnosis and too few interventions lead to oral health disparities in Māori (Stuart et al., 20lI). Most oral health professionals are non-Māori and there is no Māori oral health initiative or Oranga Niho services in Southland (Personal communication, April 3, 2019). Language barriers and a lack of cultural awareness by healthcare professionals could hinder the development of Māori participation and partnership with whānau. In general, differing beliefs and cultural norms relating to dental care can contribute to poor access to dental care in small rural communities (National Health committee, 2003). 


\section{Affordability}

In New Zealand, a dental consultation fee is likely to be more expensive than a visit to a GP (Stuart et al., 20I I). As most Mataura residents have an income of $\$ 30,000$ or less, there is a financial barrier for dental services for some whānau and immigrant families (Statistics New Zealand, 20I3). Although the dental service is publicly funded for children who meet the eligibility criteria ( 0 to 18 years), the cost of consultation fees and certain treatments - for example, orthodontic work ( $\mathrm{MOH}, 2017)$ - and travel costs (due Mataura's poor public transport system) can be a significant burden on families.

\section{Additional barriers}

We noted a lack of awareness of the local services available. Since the immigrant population has increased in Mataura, there are many parents with little knowledge of the New Zealand healthcare system and the services offered, leading to a low uptake of dental care among preschoolers in Mataura, with many children missing or delaying dental care (Personal communication, April 3, 2019). Many parents who hold a work visa and have lived in New Zealand for more than two years are unaware that their children are eligible for the publicly funded dental health service $(\mathrm{MOH}, 2017)$.

Parents play an important role in their children's oral health, and their perceptions could delay or prevent them accessing dental care for their children. Parents who avoid visiting the dentist because of past negative experiences of pain, fear or dissatisfaction represent a further barrier to achieving dental care for their children (Gordon, Dionne, \& Snyder, 1998). In addition, inadequate preparation for the first appointment could lead to fear and anxiety in children, which can delay them receiving appropriate care or lead to refusal of future dental appointments (Gordon, Dionne, \& Snyder, 1998).

In conclusion, there are many factors that influence good oral hygiene and oral health. With the delivery of more inclusive oral health programs and resources through the primary and public health sectors, New Zealand will start to see better oral health outcomes for all citizens. Investigators have made strong recommendations to develop new models of oral health and how it is delivered in order to meet the needs of low-income Māori and nonMāori clients, and to make dental care much more accessible (Broughton et al., 2013). Another intervention involves encouraging, educating and supporting small communities to fluoridate their drinking water supply to ensure that all possible steps are taken to reduce the incidence of dental caries.

\section{Resources created for Health Need I}

\section{Dental Caries}

The team working on dental caries decided to create a poster, fridge magnet and teeth-brushing chart, to be displayed in schools, preschools and community hubs, to encourage children and parents to keep the issue relevant and part of community conversations. The poster includes both images and text. The fridge magnet was designed as a daily reminder of good oral health. The brushing chart is an incentive for children to brush their teeth twice daily and to have a visual aid that would help them to remember to do so.

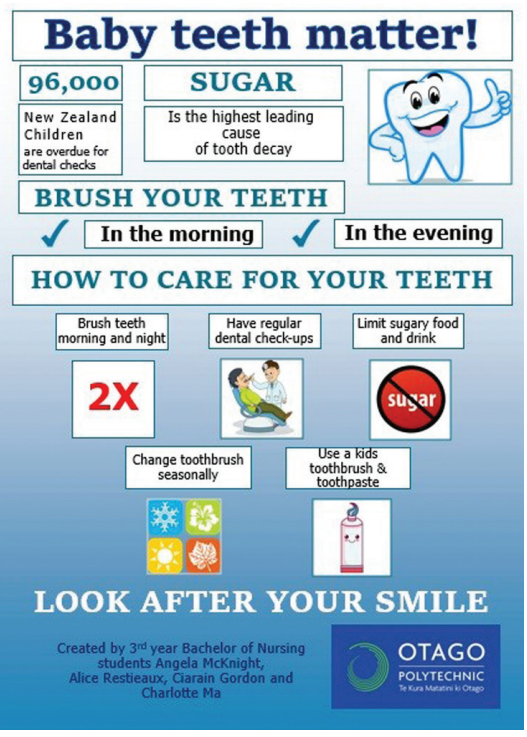

Figure 3. Children's oral health resource:Tick chart. Source: Authors. 


\section{HEALTH NEED 2 -ADOLESCENT PSYCHOSOCIAL ISSUES: DEPRESSION}

A survey of youth mental health conducted in 2012 questioned 3 percent of students in secondary school education in New Zealand (Best Practice Journal, 2015); 38 percent of female students and 23 percent of male students said they felt depressed on occasion, with 16 percent of females and 9 percent of males experiencing symptoms that had an impact on their lives (Mental Health Foundation, 2014). Unfortunately, 20 percent of young people are likely to experience a mental health issue (Mental Health Foundation, 20 I4). Depression is not always due to reactions to circumstances; if sufferers experience depression or any symptom of depression for more than two weeks, this could suggest mental illness (MacGill, 2018).

The literature suggests that adolescence is a pivotal developmental period for establishing positive health practices and resiliency for adulthood. Health practices and patterns of behaviour begun in adolescence can significantly impact the health and well-being of a person over the course of their lifetime and, conversely, unaddressed health concerns or unhealthy behaviours can contribute to the trajectory of long-term conditions in adulthood (Weber, Puskar, \& Ren, 20 I0; Curtis, Waters, \& Brindis, 20 I0).

\section{Causes}

The triggers for depression include genetics and family history, trauma, isolation, stress and the side effects of some medication. If a sibling or parent has depression, then a person has a 20-30 percent higher risk of depression, rather than the 10 percent incidence in the rest of the population (Levinson, n.d.; Psych Guides, n.d.). A traumatising event that has caused emotional turmoil can lead to a person shutting off, causing isolation which can make their depression worse (Psych Guides, n.d.), in addition to stress, which can cause emotional and mental exhaustion (Psych Guides, n.d.). Some medications have side effects that include depression; these can be reversed if the medication is stopped (Psych Guides, n.d.).

\section{Contributing factors to depression in rural adolescents}

A person's mental health is shaped by the social, economic and physical environments present at different stages of life. Social inequalities are heavily associated with many

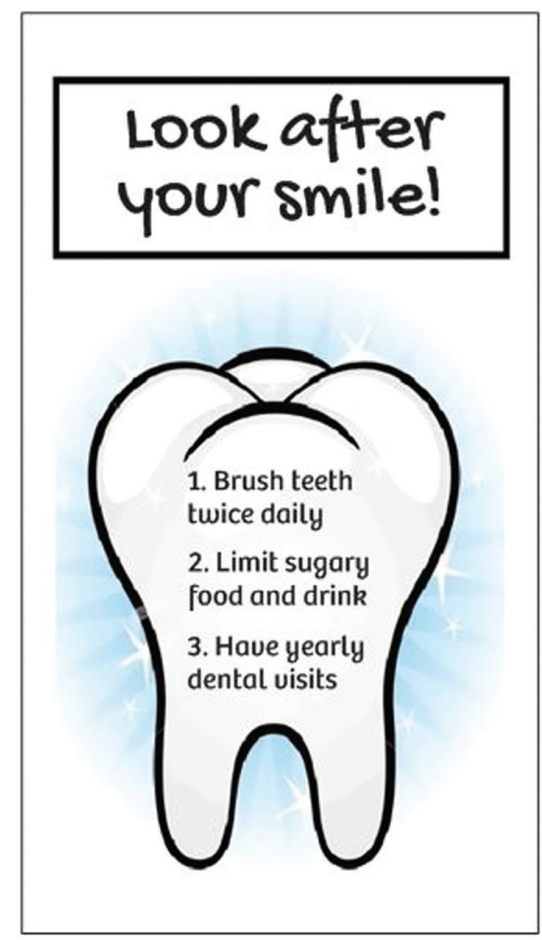

Figure 4. Children's oral health resource: Poster. Source: Authors.
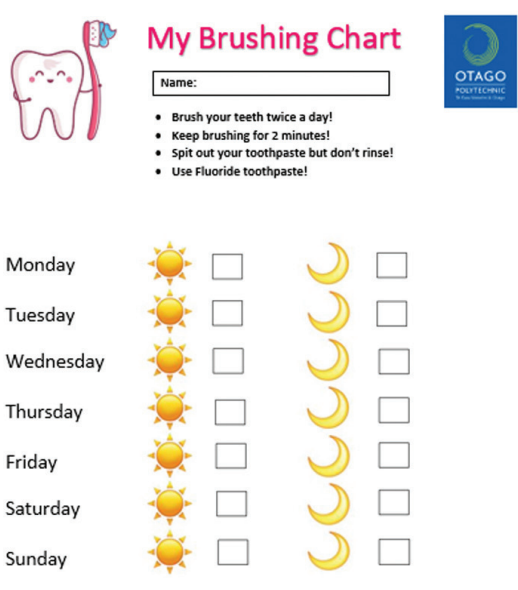

Figure 5. Children's oral health resource: Fridge magnet. Source: Authors. 
common mental health disorders - the greater the inequality, the higher the risk. The social determinants of mental health include the conditions in which people are born, work and live, as well as age and access to healthcare. These factors are in turn shaped by a set of broad external forces: state social and environmental policies, politics and economics (Allen, Balfour, Bell, \& Marmot, 20।4).

The World Health Organisation has identified some important factors that influence a person's risk of suffering mental disorders, factors that also present opportunities for intervening to reduce risk. For adolescents, these factors are:

- Life course

- Parents, families and households

- Community

- Local services

- $\quad$ National-level factors (World Health Organisation, 20I4)

\section{Short-term effects}

- Lethargy

- Fatigue

- Hypersomnia

- Insomnia

- Weight loss and loss of appetite (Psych Guides, n.d.)

- $\quad$ Sleeping issues (Best Practice Journal, 2015)

\section{Long-term effects}

- Malnutrition

- Obesity

- Decrease in short-term memory (due to the struggle to focus)

- Possibility of suicide (over 66 percent of suicides are linked to depression; Psych Guides, n.d.).

- Social isolation

The rural environment presents a unique and potentially challenging context for adolescent health. Statistically, rural people experience greater poverty and achieve lower levels of education than urban populations (Weber et al., 20 I0). Rural settings may also present barriers to healthcare for adolescents including isolation, insufficient financial resources and concerns over confidentiality within a small community setting (Curtis et al., 20 I0).

Rural communities are often close-knit; while this provides a support system for residents, it this may also function as a barrier to reaching out for help. These communities can also be highly integrated, meaning that people who are different or new arrivals may be isolated (Byrne, 20 I7). Isolation, which often correlates with loneliness, has a significant impact on mental health; there is evidence that loneliness is a predictor of depressive symptoms (Bohny, 2018).

Isolation is a significant problem in rural communities, as a consequence of their physical location and the limited services available within the community. Opportunities for treatment, recreation, health education and social inclusion can be difficult to find, circumstances which significantly impact the well-being of the community (Byrne, 20 17). In rural areas, the structure and location of the community and the relationships between its members can have a significant impact on the mental health of residents and work as barriers to seeking help. 


\section{Mental health services and initiatives}

In rural New Zealand, there are often very few support services for youth with depression. In Mataura, counselling and peer support groups are provided by the pastor of the local church; there is nothing else (Personal communication, April 3, 2019). Mental health support and access to services is lacking in many areas of New Zealand, particularly in rural areas (The Royal Australian and New Zealand College of Psychiatrists, n.d).

The recommendations of the Inquiry into Mental Health and Addiction, set up by the New Zealand government, were made in a document called Te Ara Oranga. Expanding access to and choice of services is the main recommendation of the report (Mental Health and Addiction Inquiry, 20 I9). Expanding access includes:

- agreeing to significantly increase access to publicly funded mental health and addiction services for people with mild to moderate and moderate to severe mental health and addiction needs

- $\quad$ setting a new target for access to mental health and addiction services that covers the full spectrum of need

- agreeing that access to mental health and addiction services should be based on need, so that access to all services is broad-based and prioritised according to those needs

- ensuring that people with the highest needs continue to be the priority (Mental Health and Addiction Inquiry, 2019).

The Youth Mental Health Project initiated by the Ministry of Health (20I8) includes several funded initiatives aimed at improving the mental health of youth in New Zealand. These initiatives include maintaining and expanding funding for school-based health services to decile 3 secondary schools, as well as expanding HEADSSS (Home, education/ employment, activities, drugs/alcohol, sexuality, suicide/depression, safety) wellness checks in schools and primary care settings (Ministry of Health, 20l8e). The Ministry is also focused on increasing funding to extend the current primary mental health service to all youth in the 12-19 age group and their families. The Ministry also runs a funded youth mentor service and funded mental health workshop days, which train participants to recognise and respond effectively to youth experiencing mental ill health (Ministry of Health, 20 I 8e). A review of the literature and services available to address youth mental health in New Zealand has also produced some nursing recommendations.

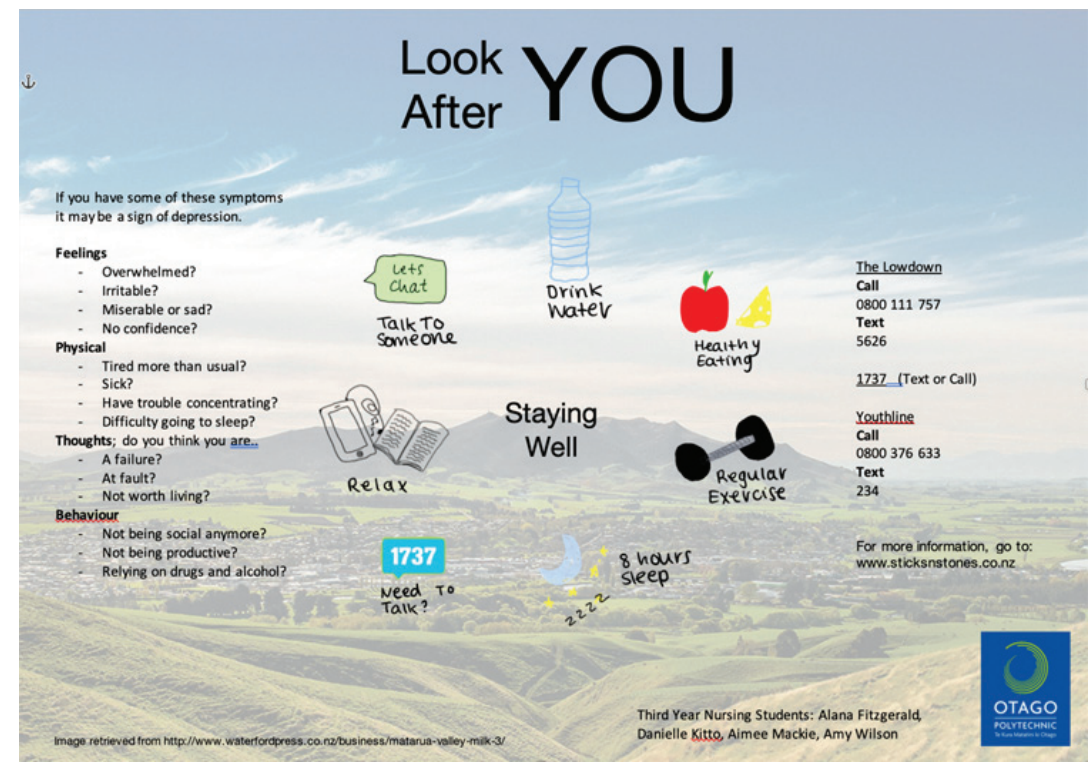

Figure 6. Youth mental health resource: Poster. Source: Authors. 

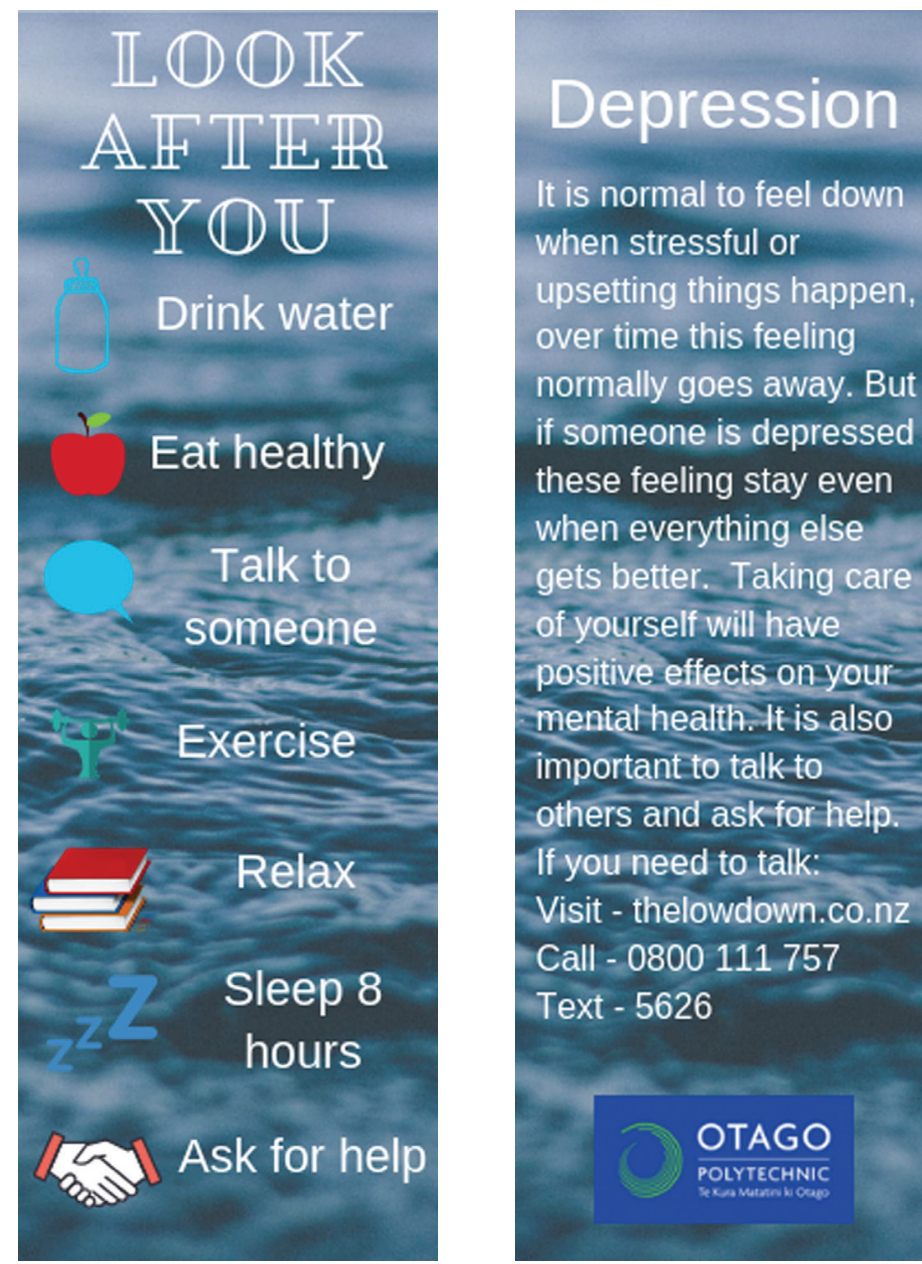

It is normal to feel down

when stressful or

upsetting things happen,

over time this feeling

normally goes away. But

if someone is depressed

these feeling stay even

when everything else

gets better. Taking care

of yourself will have

positive effects on your

mental health. It is also

important to talk to

others and ask for help.

If you need to talk:

Visit - thelowdown.co.nz

Call - 0800111757

Text - 5626

Figure 7. Youth mental health resource: Bookmark.

Source: Authors.

\section{Resources created for Health Need 2}

\section{Adolescent Depression}

The team working on adolescent depression created a bookmark and a poster. We originally wanted to create a website or a Facebook page, but found this was inappropriate due to the limited access to technology enjoyed by some members of the community. The poster contains information about the signs and symptoms of mental illness and how young people can look after themselves, presented in seven simple steps. It also includes a list of 24/7 support, with numbers to call or text when professional intervention is sought. The second resource we created was a bookmark for young people to take home, a condensed version of the poster. 


\section{REFERENCES}

Allen, J., Balfour, R., Bell, R., \& Marmot, M. (2014). Social determinants of mental health. International Review of Psychiatry, 26(4), 392-407. https://doi.org//0.3109/09540261.2014.928270

Best Practice Journal. (20I5). Addressing mental health and wellbeing in young people. Retrieved from https://bpac.org.nz/BPJ/20I5/ October/wellbeing.aspx

Bohny, S. (20|8). The isolated unwell: How mental illness and loneliness interact. Retrieved from Stuff: https://mww.stuff.co.nz/ national/health/ | 0653 | 307

Broughton, J. R., Maipi, J. T. H., Person, M., Thomson, W. M., Morgaine, K. C., Tiakiwai, S., .. Jamieson, L. M. (20I 3). Reducing disease burden and health inequalities arising from chronic disease among indigenous children: An early childhood caries intervention in Aotearoa/New Zealand. BMC Public Health, 13, 1 1 77. http://dx.doi.org.op.idm.oclc.org/ I 0.1 I 86/ I 47| -2458- 13 - 1 I 77

Bryne, L. H. S. (2017). Acknowledging rural disadvantage in mental health:Views of peer workers. Perspectives in Psychiatric Care, 52(4), 259-265.

Colgate. (n.d.). Toddler tooth decay and how to prevent it. Retrieved from https://www.colgate.com/en-us/oral-health/life-stages/ childrens-oral-care/toddler-tooth-decay-and-how-to-prevent-it-03।4

Colgate. (2019). What is fluoride? Retrieved from https://www.colgate.com/en-us/oral-health/basics/fluoride/what-is-fluoride

Curtis, A. C., Waters, C. M., \& Brindis, C. (20II). Rural adolescent health: The importance of prevention services in the rural community. The Journal of Rural Health, 27(I),60-7I.

Cury, J. A., Tenuta, L. M. A., Ribeiro, C. C. C., \& Paes Leme, A. F. (2004). The importance of fluoride dentifrices to the current dental caries prevalence in Brazil. Brazilian Dental Journal, 15(3), 167- 174.

Deykin, E.Y. (1987). Adolescent depression, alcohol and drug abuse. American Journal of Public Health, 77(2), I78-182.

Farmer, T. (201 I). Early adolescent peer ecologies in rural communities. J Youth Adolescence, 40, I I 06- I I I7.

Fluoride Free NZ. (n.d.). Sugar causes tooth decay. Retrieved from ～https:/fluoridefree.org.nz/sugar-causes-tooth-decay/

Grant, D. (20I5). Southland places - Eastern Southland. In Te Ara - The Encyclopedia of New Zealand. Retrieved from: https://teara. govt.nz/en/photograph/20178/mataura-freezing-works-and-falls

Google (n.d.). Google Maps directions for driving from Mataura to Gore. Retrieved from https://www.google.com/maps/dir/Mataura/ Gore/@-46. I 45974 I, I 68.8358774, I 2z/data=!3m l!4b I!4m I 4!4m I 3! I m5! I m I! I s0xa82cd I 5273a36cb5:0×500ef8684798 c30!2m2! I d | 68.8660 I 55!2d-46. I 934288! I m5! I m I! I s0xa82ccc729cbe5979:0×500ef8684799935!2m2! I d I 68.9458 I 9!2 d$46.0987992 ! 3 e 0$

Gordon, S., Dionne, R., \& Snyder, J. (1998). Dental fear and anxiety as a barrier to accessing oral health care among patients with special health care needs. Special Care in Dentistry, I 8(2), 88-92. https://doi.org/ / 0.1 I I I/j. I 754-4505. I 998.tb009 I0.x

Hasan, A. (2018). The caries process and the importance of fluoride: An update. Dental Health, 57(2), 25-27. Retrieved from http:// search.ebscohost.com/login.aspx?direct=true\&db=ccm\&AN=|28259| 80\&site=ehost-live

Health Point. (2019). Mataura in Southland. Retrieved from https://www.healthpoint.co.nz/public/southland/im:619496/

Health Promotion Agency. (n.d). How to treat depression \& anxiety. Retrieved from https://depression.org.nz/get-better/treatments/

Hunt, G. R., Foster Page, L. A., \& Thomson, W. M. (2018). Dental treatment of children under general anaesthesia in district health boards in New Zealand. New Zealand Dental Journal, I/4(4), I56-163. Retrieved from http://search.ebscohost.com.op.idm. oclc.org/login.asp $x$ ?direct $=$ true \&db $=c c m \& A N=\mid 33754233 \&$ site=ehost-live

Kanduti, D., Sterbenk, P., \& Artnik, B. (2016). Fluoride: A review of use and effects on health. Materia Socio-medica, 28(2), I33-I 37. https://doi.org/| 0.5455/msm.2016.28.133-137

Kulig, K. (2005). Rural youth violence: It is a public health concern! Canadian Journal of Public Health, 96(5), 357-359.

Levinson, D, F. (n.d.). Major depression and genetics. Retrieved from http://med.stanford.edu/depressiongenetics/mddandgenes.html

McLeod, H. (2016, April I3). Southland and Gore district face possible water fluoridation. Stuff. Retrieved from https://www.stuff. co.nz/national/health/78888349/southland-and-gore-districts-face-possible-water-fluoridation

Mental Health Foundation. (2014). Quick facts and stats 2014. Retrieved from https://www.mentalhealth.org.nz/assets/Uploads/ MHF-Quick-facts-and-stats-FINAL-

MacGill, M. (20/8). What is depression and what can I do about it? Retrieved from: https://www.medicalnewstoday.com/kc/ depression-causes-symptoms-treatments-8933

Messina, M. J. (20 I6). Fluoride, dental caries, and safety. Generations, 40(3), 4 I-42. Retrieved from http://search.ebscohost.com/login. aspx? direct=true\&db=ccm\&AN=| | 9 | 34599\&site=ehost-live

Ministry of Health. (2003). Improving child oral health and reducing child oral health inequalities. Retrieved from http://www.moh.govt. nz/NoteBook/nbbooks.nsf/0/4EE I 404403E04F59CC256D390076DD8C/\$file/Improving\%20child\%20oral\%20health.pdf 
Ministry of Health. (2012). Tips for a healthy smile. Retrieved from https://www.health.govt.nz/publication/tips-healthy-smile

Ministry of Health. (2014). Health literacy action plan for oral health. Retrieved from https://www.health.govt.nz/system/files/ documents/pages/cmdhb-health-literacy-action-plan.pdf

Ministry of Health. (2017). Publicly funded dental care. Retrieved from https://www.health.govt.nz/your-health/services-andsupport/health-care-services/visiting-dentist/publicly-funded-dental-care

Ministry of Health. (2018a). Caring for your pre-schooler's teeth. Retrieved from https://www.health.govt.nz/your-health/pregnancyand-kids/under-fives/3-5-years/caring-your-preschoolers-teeth

Ministry of Health. (20 I 8b). Fluoride. Retrieved from https://www.health.govt.nz/your-health/healthy-living/teeth-and-gums/fluoride

Ministry of Health. (20l8c). Oral health. Retrieved from https://www.health.govt.nz/our-work/populations/maori-health/tataukahukura-maori-health-statistics/nga-mana-hauora-tutohu-health-status-indicators/oral-health

Ministry of Health. (20l8d). Mental health. Retrieved from https://www.health.govt.nz/our-work/populations/maori-health/tataukahukura-maori-health-statistics/nga-mana-hauora-tutohu-health-status-indicators/mental-health

Ministry of Health. (20/8e). Youth mental health project initiatives. Retrieved from https://www.health.govt.nz/our-work/mentalhealth-and-addictions/youth-mental-health-project/youth-mental-health-project-initiatives\#new

Moore, D., \& Poynton, M. (2015). Review of the benefits and costs of water fluoridation in New Zealand: Report prepared for the Ministry of Health. Retrieved from https://www.health.govt.nz/system/files/documents/publications/review-benefits-costswater-fluoridation-new-zealand-apr 16.pdf

National Health Committee. (2003). Improving child oral health and reducing child oral health inequalities: Report to the Minister of Health from the Public Health Advisory Committee. Retrieved from http://www.moh.govt.nz/NoteBook/nbbooks.nsf/0/4EEI 40 4403E04F59CC256D390076DD8C/\$file/Improving\%20child\%20oral\%20health.pdf

New Zealand Dental Association (2017). NZDA consensus statement on sugary drinks. Retrieved from https://www.nzda.org.nz/ about-us/news/nzda-consensus-statement-on-sugary-drinks

Psych Guides (n.d.). Depression symptoms, causes and effects. Retrieved from https://www.psychguides.com/depression/

Royal Society of New Zealand. (2014). Health effects of water fluoridation: A review of the scientific evidence. Retrieved from https:// www.pmcsa.org.nz/wp-content/uploads/Health-effects-of-water-fluoridation-Aug20 I4.pdf

Schluter, P. J., \& Lee, M. (2016). Water fluoridation and ethnic inequities in dental caries profiles of New Zealand children aged 5 and I2-I 3 years: Analysis of national cross-sectional registry databases for the decade 2004-20 I 3. BMC Oral Health, 16. http:// dx.doi.org.op.idm.oclc.org/10.1 | 86/s | 2903-016-0180-5

Statistics New Zealand. (2013). 2013 Census: Quickstats Mataura. Retrieved from http://archive.stats.govt.nz/Census/20I3-census/ profile-and-summary-reports/quickstats-about-a-place.aspx?request_value $=|5| 6 \mid$ \&tabname=Work\&sc_device=pdf

Statistics New Zealand. (20।4). Defining urban and rural New Zealand. Retrieved from http://archive.stats.govt.nz/browse_for_stats/ Maps_and_geography/Geographic-areas/urban-rural-profile/defining-urban-rural-nz.aspx

Te Aō Marama The NZ Māori Dental Association. (2019). Position statement - Sugar sweetened beverages. Retrieved from https:// teaomarama.org.nz/images/Te_A\%C5\%8D_Marama_position_statement_on_SSBs.pdf

Thapar, A., Collishaw, S., Pine, D. S., \& Thapar,A. K. (2012). Depression in adolescence. The Lancet, 379(9820), I056-1067. https://doi. org/l0.1016/S0|40-6736(I |)6087|-4

UD/MH. (20I8). How the city affects mental health. Retrieved from https://www.urbandesignmentalhealth.com/how-the-cityaffects-mental-health.html

Weber, S., Puskar, K. R., \& Ren, D. (2010). Relationships between depressive symptoms and perceived social support, self-esteem, \& optimism in a sample of rural adolescents. Issues in Mental Health Nursing, 31 (9), 584-588.

World Health Organisation. (20/4). Social determinants of mental health. Retrieved from https://apps.who.int/iris/bitstream/ handle/ I 0665/ I | 2828/978924 I 506809_eng.\%20pdf?sequence= I

World Health Organisation. (2019b). The Ottawa charter for health promotion: Health promotion action. Retrieved from https:// www.who.int/healthpromotion/conferences/previous/ottawa/en/indexl.html

World Health Organisation. (2019c).Vulnerable groups. Retrieved from https://www.who.int/environmental_health_emergencies/ vulnerable_groups/en/ 